\title{
ESTUDOS DA LINGUAGEM: LÍNGUA E ENSINO
}

\author{
Freda Indursky
}

RESUMO: Les études du langage constituent un champs de connaisances et très hétérogène. Par conséquent, il comporte plusieurs et différentes acceptions de langue. Pour la linguistique moderne, fondée par Ferdinand de Saussure, la langue, conçue comme système, n'acoorde pas d'espace pour les marques de l'activité langagière de l'homme. L'acception benvenistienne de langue, par contre, prend en considération les interlocuteurs aussi bien que leur contexte situationnel. D'où l'on peut conclure que la langue conçue au cadre de la théorie de lénonciation établit des rapports internes et externes. Michel Pêcheux, à son tour, pour pouvoir réfléchir sur son object, le discours, conçoit l'extériorité comme constitutive de la langue et le sujet, affecté par l'inconscient et interpellé par l'idéologie, s'identifie avec cette langue à partir du contexte socio-historique dans lequel il est inscrit. Et pour que l'on puisse mieux percevoir les differences entre ces trois acceptions de langue, ces différentes perspectives théoriques seront mobilisées pour analyser un meme énoncé.

PALAVRAS-CHAVE: concepções de língua, organização da língua, ordem da língua, formação discursiva, posição-sujeito, ensino de língua

\section{APRESENTANDO A PROBLEMÁTICA}

Para começar, preciso apontar os caminhos vou trilhar: meu propósito inicial é mostrar que os Estudos da Linguagem constituem um campo de conhecimento bastante amplo e fortemente heterogêneo. Nesse campo se abrigam a teoria gerativista, a lingüística funcional, os estudos enunciativos, pragmáticos e discursivos, por exemplo. Tal diversidade conduz inevitavelmente a desenhar diferentes objetos cujas concepções de língua são igualmente diversas. Em função disso, num primeiro momento, vou esboçar um breve panorama com o propósito de observar as diferenças e limites entre três dessas concepções, a saber: a língua sistêmica, a língua da enunciação e a língua da Análise do Discurso. A seleção desses três campos e a ordem em que vão ser examinados permitem observar uma progressiva ampliação do que se compreende por língua em cada um deles, indo desde um objeto estritamente lingüístico, passando por um objeto que associa o lingüístico ao pragmático e chegando a um terceiro objeto em que o extra-lingüístico é, sempre, parte constitutiva do lingüístico.

Freda Indursky é professora titular da Universidade Federal do Rio Grande do Sul, atuando no PPG-Letras/UFRGS, na linha de pesquisa Análises Textuais e Discursivas, onde orienta mestrandos e doutorandos. 
Por outro lado, quando me refiro a diferenças e limites, não o faço para estabelecer julgamentos de valor a respeito dessas diferentes concepções de língua. Ao contrário. Isso será feito como um gesto necessário e imprescindível à reflexão sobre o ensino de língua. Dito de outra forma: não se trata, aqui, de determinar qual a melhor concepção teórica de língua, nem, muito menos, qual a pior. Trata-se mais bem de observar essa questão por um outro ângulo, bem mais interessante, que permita avaliar as implicações de cada uma dessas concepções de língua. Entendo que isso se constitui em subsídio indispensável para o fazer do professor em sua prática de ensino. Se o que ele se propõe fazer é da ordem de uma pura descrição, é a concepção sistêmica que deverá ser adotada. Se seu objetivo for o de trabalhar a língua a serviço da argumentação, interessa-lhe a concepção lingüísticopragmática de língua. Se, além de argumentar, o professor se propuser a mostrar que, através da língua, o sujeito pode identificar-se com a historicidade de certos sentidos e contrapor-se à de outros, compete-lhe trabalhar com a terceira concepção de língua. E mais: não se trata de selecionar uma delas e abandonar as demais, mas de trabalhar gradativamente cada uma dessas concepções, de modo a ampliar, cada vez mais, o leque de possibilidades que essas diferentes concepções de língua colocam à disposição de seus estudantes.

\section{A CONCEPÇ̃̃O SISTÊMICA DE LÍNGUA}

A Lingüística moderna, fundada no início do século XX por Ferdinand de Saussure, resultou das famosas dicotomias saussurianas, salientando-se, sobremodo, o famoso corte epistemológico que cindiu a linguagem em língua e fala. Nessa perspectiva, esquematicamente, pode-se dizer que língua remete a um sistema abstrato, a um sistema de valores constituído por puras diferenças, enquanto a fala remete ao uso do referido sistema. A isto podemos acrescentar que, para Saussure, a barra que opõe língua/fala separa o social do individual, o essencial do acessório e acidental. Tal separação permitiu determinar a língua e não a fala como objeto da Lingüística, pois é na língua que podem ser examinadas as relações e sistematicidades de seus elementos constituintes. Tais relações, ao abstraírem o uso e as variações dele decorrentes, são de natureza regular e homogênea, permitindo instituir um objeto idealizado no qual nada que não seja estritamente lingüístico deve ser levado em consideração. E Saussure salienta que "não só pode a ciência da língua prescindir de outros elementos da linguagem como só se torna possível quando tais elementos não estão misturados" (SAUSSURE, 1974, p.23). Ou seja: a língua, nessa concepção, é um objeto asséptico, de onde todo e qualquer elemento que não seja interno, próprio ao sistema lingüístico, nela não encontra lugar e dela deve ser excluído. Como se vê, a oposição língua/fala, princípio fundante da ciência lingüística, exclui a atividade do homem com/na língua e, nesse mesmo movimento, dela exclui toda e qualquer relação com a exterioridade.

\section{A CONCEPÇÃO LINGUÍSTICO-PRAGMÁTICA DE LÍNGUA}

Desde os anos 40, os trabalhos de Benveniste evidenciaram que muitos aspectos, relegados ao residual da fala por Ferdinand de Saussure, poderiam ser estudados em sua regularidade, permitindo examinar as marcas da atividade do homem na língua. 
Benveniste (1966, p.226-54) instaura este novo objeto de estudo, salientando que a língua possui formas que possibilitam a alguém assumir-se como locutor e, deste modo, apropriar-se da linguagem, fundando, assim, sua subjetividade à medida que, podendo dizerse EU, pode dizer Tu para um outro, instituído como seu interlocutor. Assim, ao estudar o par EU-TU, Benveniste dá início à reflexão sobre o objeto que designaria mais tarde de enunciação.

A partir desse par inicial, outros elementos lingüísticos são por ele estudados, os quais servem para marcar o espaço e o tempo do locutor da enunciação e situar o locutor face ao seu interlocutor. Todas as categorias estudadas pelo autor pertencem, de direito, à língua sistêmica, mas servem para marcar as atividades linguageiras do homem, pois, segundo o autor, "a linguagem dispõe de um conjunto de signos vazios, não referenciais em relação à 'realidade', sempre disponíveis e que se tornam plenos desde que o locutor os assuma como instância de seu discurso" (BENVENISTE, 1966, p.254). Ou seja, a enunciação mobiliza elementos que pertencem à língua, mas cujo sentido depende de fatores pragmáticos que variam de uma enunciação à outra. Tais elementos são de natureza lingüístico-pragmática - o emissor, o receptor e sua localização espaço-temporal - e constituem o contexto situacional em que se dá a enunciação. Este conjunto de signos tem por função relacionar enunciado e enunciação, vinculando o lingüístico à fala. Assim procedendo, os estudos de Benveniste recuperam elementos até então considerados residuais, os quais vão subsidiar uma nova relação com a língua. Esta língua, por conseguinte, não é mais estritamente idêntica à língua sistêmica, pois elementos extralingüísticos são associados ao lingüístico.

\section{Produzindo um primeiro contraponto}

Se compararmos a primeira concepção de língua, acima delineada, à esta segunda, veremos que a primeira desenha um objeto homogêneo, do qual estão excluídos todos os elementos que não são estritamente lingüísticos. Esta é a língua dos estudos sistêmicos. A segunda propõe um objeto diverso, pois a língua instituída pelos estudos da enunciação mobiliza elementos de natureza lingüístico-pragmática, ao levar em consideração os interlocutores e sua situação de enunciação. A primeira considera apenas as relações internas ao sistema lingüístico, enquanto a segunda interessa-se pelas relações internas e externas, decorrendo daí duas concepções de língua diversas.

\section{A CONCEPÇÃO DISCURSIVA DE LÍNGUA}

Os anos 60 vêem surgir a Análise do Discurso no campo dos Estudos da Linguagem a qual se institui questionando o corte epistemológico saussuriano (língua/fala) e propondo um deslocamento para língua/discurso.

Em seu primeiro texto, Pêcheux (1969), o fundador desse novo campo, afirma que discurso é efeito de sentido entre interlocutores. Ou seja, desde sua postulação inaugural, a exterioridade é convocada, sendo considerada como plenamente constitutiva do novo objeto. Posteriormente, o autor (PÊCHEUX \& FUCHS, 1975) revisita a noção de sujeito e 
reivindica para a Análise do Discurso um sujeito histórico, afetado pelo inconsciente e interpelado pela ideologia. Vale dizer: para este novo objeto que se inscreve no campo dos Estudos da Linguagem, a relação do discurso com a história e com o sujeito são essenciais. Segundo Pêcheux (1971), a Teoria do Discurso pertence, de direito, ao materialismo histórico. Em 1975, Pêcheux vai além e vincula o sentido à formação discursiva, questionando, desta forma, a noção de sentido literal. E mais: a forma lingüística, tal como é estudada pela lingüística, cede seu lugar, na teoria da $\mathrm{AD}$, à materialidade lingüística, historicamente determinada. Por ser assim constituída, essa materialidade não é exclusivamente lingüística. Por seu viés, o indivíduo se subjetiva e se identifica, inscrevendose em processos discursivos no âmbito dos quais produz diferentes efeitos de sentido.

De tudo quanto precede, pode-se perceber que a língua, nesse enquadramento teórico, nunca foi pensada de forma fechada, sistêmica. Língua, nesse domínio de saber, vem, desde sempre, entrelaçada à exterioridade e é concebida como uma materialidade através da qual o ideológico se manifesta. Por essa razão, "o deslize, a falha e a ambiguidade são constitutivos da língua” (PÊCHEUX, 1994, p.62).

Orlandi, em 1996, mostra que podemos tomar a língua em duas dimensões diversas, a da organização e a da ordem. A organização diz respeito às relações internas, enquanto a ordem relaciona a língua à sua exterioridade constitutiva. É, pois, com a língua, enquanto ordem, que a Análise do Discurso trabalha.

\section{Produzindo um segundo contraponto}

Cabe fazer um novo contraponto, considerando, para isso, as três concepções de língua que acabamos de examinar. A língua com que trabalha a análise do discurso não é um objeto estritamente linguiístico, como o é a língua sistêmica; tampouco é apenas um objeto lingüístico-pragmático, como a língua desenhada pela teoria da enunciação, embora tenha muito mais elementos em comum com essa última do que com a primeira. Vejamos isso de outra forma: a língua com que a $\mathrm{AD}$ trabalha mobiliza não só constituintes lingüísticos, mas também e fortemente noções que são alheias à língua sistêmica, tais como sujeito e interlocutor, elementos esses que se fazem presentes na língua da enunciação. Por outro lado, a língua da $\mathrm{AD}$ também convoca noções que são estranhas tanto à lingua sistêmica quanto à língua das teorias da enunciação, como, por exemplo, contexto sócio-histórico, ideologia, inconsciente, para apenas mencionar algumas delas.

A seguir, vou aprofundar um pouco mais o contraste entre as concepções sistêmica e discursiva $a^{l}$ de língua. Na concepção sistêmica, a língua é considerada como uma estrutura que comporta regularidades e organização. A regularidade remete para a organização interna da língua. Já a concepção discursiva de língua considera tanto a regularidade quanto a ordem, pois comporta, em seu interior, elementos que rompem com a previsibilidade sistêmica. A língua sistêmica fecha-se a tudo que não seja estritamente lingüístico, contemplando apenas o lingüístico em suas relações internas. Já a língua da AD considera

1 Ao falar em concepção discursiva de língua, estou me referindo à noção de discurso tal como foi entendida por Pêcheux e tal como tem sido formulada, desde então, por aqueles que se inscrevem em uma relação de filiação teórica com a análise de discurso por ele fundada. 
tanto o que é interno quanto o que lhe é externo, e é isto que possibilita que o imprevisível e a irregularidade venham aí encontrar espaço para significar.

Em função de tais propriedades, a língua com que trabalha a $\mathrm{AD}$ não é transparente, não pressupõe o sentido único nem o sentido literal. Sendo a exterioridade constitutiva desta concepção de língua, não há um sentido prévio que se cole sobre o modo como os fatos são discursivizados. Face a processos discursivos que promovem a co-existência de sentidos contraditórios e mesmo antagônicos entre si, devemos reconhecer que é próprio da língua, tal como entendida pela $\mathrm{AD}$, produzir sentidos duplos, contraditórios, ambivalentes. E é da natureza discusiva da língua abrigá-los.

Isto só pode ocorrer em uma concepção de língua que leva em conta a existência de sujeitos históricos nela inscritos, os quais historicizam diferentemente seus dizeres e lhes imprimem sentidos e direções de sentido nem sempre coincidentes. Sentidos estes que não se excluem, que co-existem. Não se trata, pois, de escolher entre "isto e aquilo", como diz Pêcheux (1990), tal como ocorre na língua sistêmica, para evitar casos de ambigüidade, por exemplo. Pode-se perfeitamente trabalhar com "isso e aquilo", pois, nessa concepção de língua, trabalha-se com a possibilidade do equívoco. E, ao levar tais questões em consideração, os analistas de discurso passam da organização para a ordem da língua.

\section{Encerrando a panorâmica}

A partir desse breve sobrevôo feito aqui em torno dos caminhos empreendidos pelos estudiosos das questões referentes à língua, pode-se perceber que estes estudos são muito diferenciados entre si e, por conseguinte, os estudos da linguagem não constituem um corpo uniforme e homogêneo de conhecimentos. Ao contrário, neste campo abrigam-se pressupostos teóricos bastante diferenciados, formulações teóricas bem distintas, onde se recortam, não uma língua única e uniforme, mas várias concepções de língua que não só não se superpõem como até mesmo podem vir a antagonizar-se, muito embora todos reivindiquem a língua como objeto de estudo. É por esta razão que, para pensar o ensino, se faz necessária uma discussão prévia sobre, pelo menos, algumas destas concepções ${ }^{2}$. Se não soubermos de que língua falamos, quando falamos em língua, então não estaremos suficientemente preparados para as práticas que o ensino demanda. Pensar tais questões, em meu entender, precede necessária e obrigatoriamente toda e qualquer prática de ensino, seja para refletir sobre a língua, seja para conduzir uma prática da leitura ou, ainda, no momento de orientar ou examinar a produção de textos.

\section{FAZENDO A PASSAGEM DA TEORIA PARA A PRÁTICA ANALÍTICA}

Para ilustrar tais diferenças e limites, mostro, a seguir, como é possível produzir análises diferenciadas de uma mesma sequiência, em função da concepção de língua adotada. Vou fazer três análises de uma mesma materialidade linguiística, alicerçadas em cada uma das concepções de língua que acabamos de esboçar. A sequiência a ser analisada foi extraída

2 Vários outros contrastes podem ser feitos. Eu limitei-me, aqui, a contrastar três concepções que vão progressivamente ampliando o que entendem como constitutivo do objeto-língua. 
de uma matéria assinada por Luiz Antônio Araújo. Trata-se do chapéu da notícia que foi publicada na Zero Hora (ZH) de 31/12/1999³.

\section{Uma análise à luz da concepção sistêmica de língua} uma frase:

Consideremos, para nossa pimeira análise, a referida sequiência, tomada aqui como

(1) O Piratini implantou o Orçamento Participativo, mas não conseguiu cumprir a maioria das promessas de campanha

Esta frase será submetida, na presente seção, a uma análise que levará em conta apenas as premissas da língua sistêmica. Por conseguinte, seu exame incidirá sobre suas relações internas.

Para tanto, vou apresentar uma breve análise sintática, utilizando os conhecimentos que uma gramática de língua oferece, o que será suficiente para mostrar a que me refiro quando falo em relações internas à frase. Ao mesmo tempo, essa análise possibilitará estabelecer um paralelo com as demais análises que se seguirão. Vejamos, pois, essa análise.

Trata-se de um período constituído de duas orações:

O Piratini implantou o Orçamento Participativo; e

O Piratini não conseguiu cumprir a maioria das promessas de campanha.

Esse período é composto por coordenação e estas duas orações estão conectadas entre si pela conjunção coordenativa adversativa mas. Por conseguite, trata-se de um período composto por coordenação e a segunda oração é coordenada, sindética, adversativa, em decorrência da classificação prévia da referida conjunção.

Pode-se, pois, afirmar que fazer uma análise à luz de uma concepção sistêmica de língua, nos conduz a dois movimentos, dos quais o primeiro consiste em decompor o todo em seus elementos constituintes. No caso da análise de (1), examinei como o período está constituído. Para tanto, desdobrei o período em suas orações constituintes. E, a seguir, classifiquei a conjunção e o tipo de relação que as duas orações estabelecem entre si.

Poderia, ainda, fazer uma análise sintática interna às duas orações, decompondo-as, por sua vez, em seus elementos constituintes $(\mathrm{SN}+\mathrm{SV})$, que, a seu turno, poderiam ser decompostos, uma vez mais. Mas, para os propósitos que aqui me movem, a pequena análise realizada é mais do que suficiente. Através dela, podemos visualizar o que se entende por relações internas.

\footnotetext{
3 Esta seqüência discursiva foi publicada no balanço de fim de ano realizado por Zero Hora (ZH), jornal diário de Porto Alegre. Este balanço do ano de 1999 coincide igualmente com o término do primeiro ano do governador petista, Olívio Dutra, no Estado do Rio Grande do Sul. Ou seja: o balanço de fim de ano foi o mote que deu lugar ao referido jornal para realizar efetivamente um balanço deste primeiro ano de governo de Olívio Dutra. Situada a sequiência, interessa-me justificá-la no âmbito deste trabalho. No ano de 2007, ZH comemorou 50 anos de atividades na Imprensa Gaúcha. Como parte dos festejos, publicou um caderno especial alusivo à data e organizou uma exposição comemorativa. Como já é sabido, teoricamente entendemos que a memória discursiva é lacunar. Só à luz de sua natureza lacunar é possível entender que ZH não tenha marcado sua participação muito ativa durante o regime militar. Da mesma forma que é esta mesma natureza lacunar que explica porque, em sua exposição comemorativa, fatos como a fundação do PT e a vitória de Olívio Dutra, como governador do Estado do Rio Grande do Sul, foram "esquecidos". Tal esquecimento, que é da ordem da determinação histórica do lugar social de onde este sujeito ideológico produz seu jornal e sua exposição, é que determinou, por sua vez, de minha parte, como pesquisadora, a busca desta materialidade discursiva para proceder as análises que se seguirão.
} 
Uma vez decompostos os elementos constituintes, o passo seguinte nos conduz ao segundo movimento que uma análise dessa natureza pode oferecer e que consiste em classificar os constituintes identificados. No caso da análise precedente, o período e as orações foram classificadas. E vimos tratar-se de um período composto por coordenação; a coordenação é do tipo sindético, isto é, apresenta uma conjunção; a referida conjunção, que é adversativa, torna a relação entre as duas orações igualmente adversativa.

E esse é o limite dessa análise. Ou seja: seu resultado é a classificação das orações que constituem o referido período. Em suma: uma análise sintática decompõe o todo em partes para estabelecer a função e/ou classificar os elementos que constituem este todo. Este é o propósito de uma análise que toma a língua sistêmica como suporte para suas investigações: esta análise permite conhecer e compreender as funções sintáticas dos elementos lingüísticos constituintes de uma frase. Vale dizer, os resultados de tal análise são meramente classificatórios e descritivos.

Passemos à segunda análise e seus resultados.

\section{Uma análise à luz da concepção enunciativa de língua}

Para realizar nossa segunda análise, vamos mobilizar a concepção enunciativa de língua. Tomemos a mesma seqüência que acabamos de analisar, mas, agora, por estarmos mobilizando uma concepção lingüístico-pragmática, o objeto de análise não é mais considerado uma frase, mas um enunciado que guarda em si as marcas de sua enunciação. Numa concepção de língua deste tipo, as relações não são mais puramente lingüísticas. Elas são, a um só tempo, lingüísticas e extra-lingüísticas. E, em um contexto desta natureza, as análises não se limitam a trabalhar as relações internas (tal como em (1)). A natureza da língua também não é mais a mesma. Feitas essas ressalvas, passemos à analise do enunciado (2).

(2) O Piratini implantou o Orçamento Participativo, mas não conseguiu cumprir a maioria das promessas de campanha

Se, na análise da frase (1), não interessava saber quem disse que $O$ Piratini implantou o Orçamento Participativo, mas não conseguiu cumprir a maioria das promessas de campanha, porque, para responder a esta questão, fazia-se necessário ultrapassar o contexto lingüístico, extrapolar as relações internas à frase, agora, para analisar (2), à luz de uma concepção enunciativa de língua, esta informação não só é imprescindível, como também o é saber para quem o locutor dirigiu este enunciado, quando o produziu, e onde o fez.

Como dissemos mais acima, esta seqüência foi retirada de uma matéria assinada por Luiz Antônio Araújo e publicada pelo Jornal Zero Hora (ZH) no último dia do ano de 1999. Portanto, esta matéria dirige-se aos leitores de $\mathrm{ZH}$, de modo geral, e aos leitores interessados pelo balanço feito pelo jornal sobre o ano de 1999, mais especificamente. Porém, mais particularmente ainda, destina-se aos leitores interessados no balanço de $\mathrm{ZH}$ sobre o primeiro ano de governo do petista Olívio Dutra, no Estado do Rio Grande do Sul. Este é, pois, o contexto situacional em que (2) se inscreve. E (2) será designado, daqui em diante, de enunciado. 
Uma análise que mobiliza uma concepção lingüístico-pragmática de língua vai necessariamente relacionar o lingüístico, que pertence às relações internas desse eniunciado, com o pragmático, que se situa na relação entre este material lingüístico e a sua exterioridade. Ou seja: as relações não serão mais de natureza estritamente sistêmica, pois a exterioridade é convocada a igual título que as relações internas. Vejamos, pois, como se processa esta análise. Para tanto, vou fazer uma análise semântico-argumentativa, com base em Ducrot (1984).

Uma análise deste tipo vai tomar o enunciado (2) e desdobrá-lo em seus dois enunciados constitutivos e atribuir cada um dos enunciados obtidos a dois enunciadores diversos, E1 e E2.

Fazendo um pequeno parênteses: é possível perceber que este primeiro gesto analítico já aponta para uma radical diferença com a análise feita em (1), pois, desde o início, o lingüístico está sendo associado ao extra-lingüístico, ao mobilizar os enunciadores desses dois enunciados. Mas, fechemos esse breve parênteses e voltemos à nossa análise.

$\mathrm{O}$ primeiro enunciado - O Piratini implantou o Orçamento Participativo - é atribuído a um enunciador E1;

e o segundo enunciado - $O$ Piratini não conseguiu cumprir a maioria das promessas de campanha - é atribuído a um enunciador E2.

Observemos inicialmente que o sentido do primeiro enunciado, tomado isoladamente, pode levar-nos a supor que este enunciado aponta para uma conclusão positiva sobre o primeiro ano do governo Olívio Dutra: se o Piratini implantou o Orçamento Participativo então ele está fazendo um governo satisfatório e está conseguindo cumprir suas promessas de campanha. Ou seja, o enunciado produzido por este primeiro enunciador aponta para uma avaliação positiva do primeiro ano do governo Olívio Dutra. E esta seria efetivamente a avaliação de seu primeiro ano de mandato, não fosse a continuação desse enunciado. Vejamos então a continuidade desta análise.

O enunciado atribuído a um primeiro enunciador está ligado ao enunciado produzido por um segundo enunciador pelo operador argumentativo mas que tem por função inverter a direção de sentido e frustrar a conclusão apontada pelo primeiro enunciador. De fato, o operador argumentaivo mas, ao inverter a direção dos sentidos, conduz a uma conclusão oposta àquela do primeiro enunciado: o Piratini não conseguiu cumprir a maioria das promessas de campanha. Ou seja, a avaliação deste primeiro ano do mandato de Olívio Dutra, que inicialmente parecia ser positiva, como vimos mais acima, de fato não o é.

E esta análise nos mostra que o locutor (que pode ser tomado como o jornalista que assina a matéria ou como o próprio jornal) mobiliza as vozes desses dois enunciadores diversos e com objetivos diferentes. O primeiro, que faz uma avaliação positiva do primeiro ano do governo Olívio; e o segundo, que faz uma avaliação negativa deste mesmo período de governo. Este locutor mobiliza a voz do primeiro enunciador, mas com ela não se identifica. Ao contrário. Ele mobiliza esta voz apenas para desconsiderá-la, para mostrar que suas ponderações são insuficientes para uma boa avaliação do referido governo. Vale dizer: ele mobiliza o argumento desse primeiro enunciador para desqualificá-lo. Sua identificação efetivamente se dá com o segundo enunciador que diz que a maioria das promessas de campanha não foi cumprida. O que lhe permite desconsiderar o sentido de E1 
e a conclusão para a qual estava se dirigindo inicialmente é o uso do operador argumentativo mas. É pelo viés desse operador que se dá a desqualificação dos sentidos produzidos pelo enunciado de E1 e é esse mesmo operador que produz o redirecionamento para o sentido do enunciado de E2. E deste redirecionamento resulta uma avaliação absolutamente desfavorável para o primeiro ano do governo Olívio.

Produzindo um contraponto entre as concepções sistêmica e lingüístico-prágmálica de língua

A comparação das análises efetuadas a partir de (1) e (2) aponta com clareza que (1) trabalha com o nexo lingüístico mas, procurando perceber como ele conecta duas orações entre si com o propósito de classificar esta conexão. Ou seja, este tipo de análise ocupa-se em classificar as orações, trabalhando com a sintaxe.

Já a análise de (2), promove alguns deslocamentos importantes, a saber:

- também desdobra o enunciado em dois, mas, ao fazê-lo, vai associar os enunciados resultantes dessa divisão a dois enunciadores diversos, ou seja, vai mostrar que esses enunciados representam pontos de vista distintos que podem ser atrubuídos a dois enunciadores diversos;

- também parte do mas, mas não o considera mais como um conector lingüístico de orações, nem busca apenas classificá-lo. Em (2), o mas é tomado como um operador argumentativo e sua função não é mais a de ligar orações para compor um período, mas é a de examinar os sentidos diferentes que foram mobilizados para organizar a argumentação do locutor. Mais especificamente, este operador argumentativo mostra como o locutor trabalha com diferentes sentidos, indica como o locutor produz a orientação dos sentidos, e aponta para o ponto de vista do locutor ( $O$ Piratini não conseguiu cumprir a maioria das promessas de campanha), sem, no entanto, ocultar que existe um outro ponto de vista em circulação que, neste processo argumentativo, está sendo desqualificado ( $O$ Piratini implantou o Orçamento Participativo). E é este, exatamente, o papel do operador argumentativo mas: descartar o ponto de vista de um enunciador (E1), e mostrar que o locutor identifica-se com um ponto de vista diverso, oriundo de um outro enunciador, de E2;

- ao mobilizar os enunciadores E1 e E2, passa a associar o lingüístico (os enunciados) ao extra-lingüístico (os enunciadores); assim procedendo, deixa-se de lado a observação estrita das relações sintáticas, que são internas à língua, como vimos em (1), e parte-se para as relações lingüístico-pragmáticas da língua, as quais conduzem para o plano semântico, mobilizando pontos de vista divergentes de dois diferentes enunciadores.

Como vimos, a seqüência examinada em (2) é a mesma que aquela de (1); o nexo também é o mesmo, mas os resultados da análise são diversos, porque mobilizam concepções de língua diferentes. De um lado, temos a sintaxe e um nexo de ligação entre orações; do outro, temos a semântica e um operador argumentativo que relaciona diferentes argumentos. Os resultados são diversos porque trabalha-se com concepções de língua diferentes. Por conseguinte, há uma diferença substantiva entre os resultados produzidos pela primeira e pela segunda análise, pois passa-se da sintaxe para a semântica. Passemos, agora, à terceira análise. 
Uma análise à luz da concepção discursiva de língua

Vejamos, a seguir, como fica a análise desta mesma seqüência quando um terceiro tipo de língua, que considera a historicidade dos sentidos produzidos por sujeitos ideologicamente constituídos, é mobilizada.

Nesta terceira análise, vamos considerar nossa seqüência como um enunciado dividido entre duas posições-sujeito (COURTINE, 1981) ideologicamente constituídas e inscritas em duas formações discursivas (FD) que antagonizam entre si. Esse enunciado, ao dividir-se entre essas duas posições-sujeito, mobiliza dois diferentes enunciados discursivos. Trata-se do que Courtine (1981) chamou de enunciado dividido. Vejamos a análise em (3).

(3) O Piratini implantou o Orçamento Participativo, mas não cumpriu a maioria das promessas de campanha.

Este enunciado discursivo está dividido entre duas posições-sujeito ideologicamente distintas, inscritas em duas FD divergentes, que chamaremos de FDX e FDY, respectivamente:

PS 1: O Piratini implantou o Orçamento Participativo - FDX

PS 2: O Piratini não cumpriu a maioria das promessas de campanha - FDY

Esse enunciado divide-se em torno de um saber que provém de uma das práticas políticas do PT. A prática do Orçamento Participativo (OP), implantado pelo PT no Governo municípal de Porto Alegre, quando Olívio foi seu Prefeito, foi levada ao Estado do Rio Grande do Sul pelo mesmo Olívio Dutra, quando ele assumiu o Governo do Rio Grande do Sul. Essa prática mobilizou fortemente os gaúchos que se dividiram entre aqueles que a defendiam e com ela se identificavam e aqueles que desejavam vê-la suprimida.

A mobilização deste saber e desta prática em um enunciado dividido que funciona como o chapéu da matéria em análise, mostra que ZH também tomou posição em relação a esse fazer político de Olívio Dutra, em seu primeiro ano à frente do Governo do Rio Grande do Sul.

Esse enunciado dividido indica, com muita clareza, que o sujeito que enuncia a partir do Lugar Discursivo de ZH não se identifica com a com a Formação Ideológica que sustenta esta Formação Discursiva, nem se identifica com os saberes, práticas e efeitos de sentido que emanam desta Formação Discursiva (É o povo que deve deliberar sobre o modo como as verbas do Orçamento do Estado devem ser gastas). E, por não identificar-se com ela, seu dizer desloca-se para o seu lugar social, para sua Formação Discursiva e mostra, a partir de PS2, que não considera o OP um feito suficientemente importante para que a avaliação do primeiro ano do governo Olívio seja positiva. E isso ocorre porque a Formação Ideológica que formata os saberes e efeitos de sentido de FDY é diversa ( $O$ povo não tem capacidade nem tem conhecimentos técnicos suficientes para gerir o Orçamento do Estado. Essas decisões são de ordem técnica).

Dessa forma, o enunciado dividido em análise representa o ruído proveniente das forças em confronto no social: de um lado, o OP foi implantado no Estado e, dessa forma, Olívio cumpriu uma de suas mais fortes promessas de campanha. É disso que o primeiro 
enunciado trata, retomando, dessa forma, um enunciado em circulação - $O$ Piratini implantou o Orçamento Participativo. Esse enunciado traz as vozes daqueles que se identificam com PS1, inscrita em uma FDX, lugar em que esse feito é tomado como altamente positivo e, conseqüentemente, a avaliação do primeiro ano de governo é muito positiva. Por outro lado, o cumprimento dessa promessa política não parece suficientemente satisfatório, quando examinado a partir da segunda posição-sujeito, inscrita em uma FDY, que discorda das ações e práticas de Olivío. E é desse outro lugar discursivo, de PS2, que o segundo enunciado em circulação é produzido - O Piratini não cumpriu a maioria das promessas de campanha. E, desse lugar, a avaliação do primeiro ano do governo de Olívio não é boa. Percebe-se, pois, que PS2 antagoniza diretamente com PS1.

Como se vê, essa análise leva em consideração o contexto sócio-histórico em que o sujeito do discurso de $\mathrm{ZH}$ produziu o enunciado em análise. E mais: essa análise recupera, através desse enunciado dividido, o confronto entre diferentes sujeitos históricos, ideologicamente constituídos. Dito de outra forma: é ainda a partir de elementos da língua que essa análise está sendo produzida, mas aqui a exterioridade é constitutiva dessa língua. Retomemos a análise.

Nesse ponto, cabe perguntar: qual o funcionamento discursivo de mas numa análise que mobiliza uma concepção de língua deste tipo. Aqui, o mas tem um funcionamento bastante específico. Mas, nessa terceira análise, constrói uma fronteira entre saberes ideologicamente antagônicos reunidos em um enunciado dividido. Diria mais: para poder criticar o Governo Olívio, para poder dizer que ele não está cumprindo suas promessas de campanha, o sujeito deste discurso necessita admitir que a promessa de implantação do OP foi cumprida. No entanto, ao fazê-lo, desqualifica esta ação governamental, mostrando que isto não é suficiente para fazer uma avaliação positiva deste primeiro ano de governo.

Estamos, pois, frente a um discurso que mobiliza duas posições-sujeito em confronto, revelando que se trata, de fato, de uma disputa de sentidos. O sujeito do discurso, ao sinalizar a fronteira entre estes dois discursos através de mas, produz um duplo movimento: em primeiro lugar, desqualifica o OP e, juntamente com ele, o Governo que o implantou, mostrando que isso é absolutamnte insuficiente, para não dizer nulo ou negativo, para uma avaliação positiva; em segundo lugar, o mas promove o deslizamento de PS1, que se identifica com o OP, para PS2, que critica o referido orçamento. Dito de outra forma: mas funciona como um operador discursivo que promove o deslizamento de uma Formação Discursiva para outra ${ }^{4}$. E, assim procedento, mas reproduz discursivamente o embate que se trava na arena política do Rio Grande do Sul, naquele momento.

Produzindo um contraponto entre as concepções sistêmica, lingüístico-prágmálica e discursiva de língua

Como é possível perceber, há diferenças importantes entre as análises produzidas em (1), (2) e (3). Nesta terceira perspectiva, não interessa examinar, como foi feito em (1), a

\footnotetext{
4

Em trabalhos anterores $(1997,20028$ entre outros) pude apontar que o mas pode cumprir igualmente uma outra função: a de opor diferentes posições-sujeito inscritas em uma mesma formação discursiva. Neste caso, em lugar de produzir o deslizamento de uma FD a outra, o mas produz o deslizamento de uma posição-sujeito a outra. Neste segundo caso, entendemos que também se trata de um enunciado dividido, não mais entre saberes antagônicos, mas entre subjetividades contraditórias.
} 
função sintática do nexo língüístico mas. Nem classificar as orações por ele relacionadas. Uma análise desse tipo apaga a exterioridade.

A segunda concepção de língua que examinamos não elimina a exterioridade, à medida que envolve interlocutores e enunciadores. Nessa segunda concepção de língua, mostramos que há um deslocamento no foco das análises, pois o nexo coordenativo da sintaxe, tal como vimos em(1), é repensado a partir de outro funcionamento. Nessa segunda concepção, ele é entendido como um operador argumentativo e, dessa forma, deixa-se de fazer uma simples classificação de orações para refletir sobre o uso que o locutor faz desse nexo e os sentidos que daí decorrem. Ao passar da sintaxe para a semântica, salienta-se como é possível usar a língua para produzir sentidos, para organizar argumentos, para relacionar-se com um outro locutor, para defender um ponto de vista. Esse tipo de análise muda o enfoque da primeira e é muito mais próximo da terceira concepção que analisamos. Entretanto ela encontra aqui seu limite, pois não tem como propósito alcançar a ideologia que subjaz aos sentidos que os sujeitos, sob seu efeito, produzem.

Já a terceira análise produziu um deslocamento importante, pois considera que a língua, não apenas é capaz de organizar os argumentos de um locutor, como ocorre em (2), mas sobretudo que ela é o lugar material onde sujeitos socialmente determinados se relacionam e freqüentemente estabelecem um verdadeiro embate. Aqui o mas, entendido como um operador discursivo, estabelece fronteira entre posições-sujeito, entre formações discursivas. A língua, nesta perspectiva, é a materialidade através da qual são capturados os rumores provenientes do social, os quais se expressam em processos semânticos que não são transparentes, que demandam interpretação. Em suma: é pelo viés da língua que são tomadas diferentes posições-sujeito. Neste enquadramento teórico, a língua deixa de ser formal e sistêmica e sua sintaxe cessa de ser classificatória para tornar-se o lugar material em que sujeitos históricos produzem diferentes efeitos de sentido no interior de processos discursivos inscritos em diferentes enquadramentos ideológicos.

\section{PRODUZINDO UM EFEITO DE CONCLUSÃO}

Toda esta reflexão pode e deve ser canalizada para iluminar a prática do ensino de línguas. Com isto, não quero dizer que tais teorias devem ser "despejadas" sobre os alunos. Mas, entendo que, se o professor souber que não há uma única concepção de língua, nem de contexto, isto já pode afetar, e muito, a qualidade de seu ensino.

Indo um pouco além: não estou pregando que se deixe de ensinar sintaxe. Ao contrário. Mas estou dizendo que é possível deslizar de uma análise sintática para uma análise semântica para que os alunos melhor entendam como os nexos lingüísticos funcionam semanticamente. Diria que, pelo menos isto, já seria muito bom e o resultado disso poderia ainda reverter para uma melhor compreensão das classificações que a sintaxe formal provê. Saber identificar como a classificação sintática funciona semanticamente é um avanço e isto é da ordem de práticas de ensino. Produzir tal comparação/reflexão pode reverter tanto para a leitura de textos como para a sua produção.

A terceira concepção é igualmente importante para que se compreenda que cada um daqueles enunciados representam, de fato, diferentes tomadas ideológicas de posição. Ou seja: compete mostrar que a língua não é neutra, que a mesma língua e a mesma contrução 
sintática podem defender diferentes tomadas de posição, assumidas por sujeitos ideologicamente antagônicos, de tal forma que o enunciado dividido, anteriormente analisado em (3), poderia ter seus enunciados constitutivos invertidos, como segue em (4):

\section{(4) A maioria das promessas de campanha não foram cumpridas, mas o Piratini} implantou o Orçamento Participativo.

Se fôssemos fazer uma análise sintática da sequiência (4), não haveria nenhuma diferença entre os resultados obtidos em (1): veríamos que se trata de um período composto por coordenação, cujas orações são coordenadas e a relação que estabelecem entre si pelo viés de mas é de natureza adversativa. Seria apenas mais um exercício de classificação, com resultados idênticos ao obtido na primeira análise (1).

Vejamos agora a analise de (4), a partir da concepção lingüístico-pragmática. Diferenças imediatas podem ser percebidas, pois, embora o locutor tenha agenciado os mesmos enunciados em circulação, sua ordenação foi diferente e isso indica que, dessa vez, a E1 é atribuído o enunciado discursivo A maioria das promessas de campanha não foram cumpridas; e, a E2, foi atribuído o enunciado $O$ Piratini implantou o Orçamento Participativo. Essa inversão na ordem dos enunciados aponta para uma conclusão diferente daquela obtida em (2). Ou seja: a organização da argumentação é diversa e a conclusão para a qual o operador argumentativo mas redireciona os sentidos também o é. Contrastando a análise de (2) com a análise de (4), percebe-se que, em (2), o Governo de Olívio é avaliado negativamente, ao passo que, em (4), o governo de Olívio é avaliado positivamente.

No meu entender, essa inversão é extremamente importante para iluminar as diferenças e os limites entre uma análise sintática e uma análise semântica.

Por fim, se fizéssemos uma análise de (4) a partir da concepção discursiva de língua, encontraríamos o mesmo resultado obtido em (3) até um determinado momento: o operador discursivo mas faz fronteira entre formações discursivas divergentes, entre posições-sujeito ideologicamente antagônicas. Também aqui o mas promove o deslizamento de uma tomada de posição para outra, de uma formação discursiva para outra. Mas é a partir deste ponto que aparecem as diferenças: a tomada de posição do sujeito, em (4), é diversa daquela mobilizada em três. Em (4), o sujeito identifica-se com a FD que contém os saberes do Governo Olívio que é diametralmente oposta àquela com que o sujeito se identifica em (3), pois lá ele se opõe às práticas do Governo PT. Trata-se, pois, de sujeitos ideologicamente diversos: o sujeito de (4) antagoniza com o sujeito de (3) e, com ele, disputa sentidos.

Como se vê, por essas análises, a sintaxe não é neutra numa língua que é tomada como lugar material de realização de processos semânticos diversos e antagônicos. Neste sentido, podemos dizer que uma língua que é capaz de dar conta de diferenças ideológicas, é, de direito, uma língua que se apresenta como forma material: ela pode dar conta de diferentes processos discursivos que desenham um litígio ideológico. Isto distingue a concepção discursiva de língua das concepções sistêmica e enunciativa.

Em suma: pode-se perceber que estas três diferentes concepções de língua apresentam maior ou menor complexidade, maior ou menor contato com a exterioridade, maior ou menor filtro em relação ao que entendem como elemento constitutivo da língua, ou seja, vão desenhando diferenças e limites. E, diante deste campo diversificado, estas 
questões devem perpassar nossas reflexões quando pensamos nas práticas que envolvem a reflexão sobre língua em sala de aula.

Não considero que estas questões teóricas devam fazer parte diretamente dos programas de ensino na escola. Mas pretendo que devam fazer parte da formação do futuro professor de língua, materna e/ou estrangeira. Entendo-as como essenciais para a formação do professor. Todo professor e/ou futuro professor deve perceber com clareza que a língua sistêmica e transparente é uma concepção dentre outras e não $a$ única concepção. A língua sistêmica mostra como a língua funciona, é muito importante, mas, dependendo do que se pretenda realizar com os alunos, não basta. Depois de saber como a língua sistêmica funciona, é preciso examinar seu funcionamento semântico e/ou discursivo e, a partir dele(s), perceber os sentidos ou efeitos de sentido que tais funcionamentos produzem. É preciso compreender os processos semânticos e/ou discursivos que se engendram a partir de e sobre tais funcionamentos da língua. Só possuindo este conhecimento é que o professor vai estar instrumentado para entrar em sala de aula e ajudar seus alunos a refletir sobre a língua, a interpretar os sentidos e efeitos de sentidos que decorrem de diferentes enunciados e textos. Enfim: só assim seus alunos saberão, por sua vez, usar a língua para produzir sentidos em suas diferentes atividades dentro e fora da escola.

\section{BIBLIOGRAFIA}

BENVENISTE, Emile. Problèmes de linguistique générale. Paris, Gallimard, 1966.

COURTINE, Jean-Jacques. Quelques problèmes théoriques et méthodologiques en anlyses du discours. Langages, n.62, p.9-127, juin, 1981.

DUCROT, Oswald. (1984). Esboço de uma teoria polifônica da enunciação. In: $O$ dizer e o dito. Campinas, Pontes, 1987.

INDURSKY, Freda. A fala dos quartéis e as outras vozes. Campinas, Ed. da UNICAMP, 1997.

Unicidade, desdobramento, fragmentação: a trajetória da noção de sujeito em Análise do Discurso. In: MITTMANN, Solange; GRIGOLETTO, Evandra; CAZARIN, Ercília Ana (orgs.). Práticas discursivas e identitárias; sujeito e língua. Porto Alegre, Nova Prova, PPG-LETRAS/UFRGS, 2008. (Col. Ensaios, 22).

ORLANDI, Eni P. A Interpretação; autoria, leitura e feitos do trabalho simbólico. Petrópolis, Vozes, 1996.

PÊCHEUX, Michel. L'analyse automatique du discours. Paris, Dunot, 1969. Trad. Bras.: GADET \& HAK (org.). Por uma análise automática do discurso. Campinas, Ed. da UNICAMP, 1990.

. Langue, "langages", discours. L'Humanité, 15/10/71. p.8.

. Les vérités de la Palice. Paris, Maspéro, 1975. Trad. Bras.: Semântica e discurso.

Campinas, Ed. da UNICAMP, 1988.

. Ler o arquivo hoje. In: ORLANDI, Eni P.(org.) Gestos de leitura. Campinas, Ed. da

UNICAMP, 1994.

(1983). Discurso: estrutura ou acontecimento. Campinas, Pontes, 1990. 
PÊCHEUX, Michel. \& FUCHS, Cathérine. Mises au point et perspectives à propos de l'analyse automatique du discours. Langages, n. 37, p. 7-80, mars, 1975. Trad.Bras.: GADET \& HAK (org.). Por uma análise automática do discurso. Campinas, Ed. da UNICAMP, 1990.

SAUSSURE, Ferdinand. Curso de lingüística geral. São Paulo, Cultrix,1974. 